\begin{tabular}{|l|l|}
\hline Title: & $\begin{array}{l}\text { The levels-of-approximation approach in MC 2010: application to punching } \\
\text { shear provisions }\end{array}$ \\
\hline Authors: & Muttoni A., Fernández Ruiz M. \\
\hline Published in: & Structural Concrete \\
\hline $\begin{array}{l}\text { Volume: } \\
\text { Pages: }\end{array}$ & $\begin{array}{l}\text { Vol. } 13 \\
\text { pp. } 32-41\end{array}$ \\
\hline Year of publication: & 2012 \\
\hline $\begin{array}{l}\text { Type of publication: } \\
\text { EPFL InfoScience link: }\end{array}$ & $\begin{array}{l}\text { Peer reviewed journal article } \\
\text { http://infoscience.epfl.ch/record/175972 }\end{array}$ \\
\hline
\end{tabular}

\begin{tabular}{|l|l|}
\hline Please quote as: & Muttoni A., Fernández Ruiz M., The levels-of-approximation approach in MC \\
& 2010: application to punching shear provisions, Structural Concrete, Vol. 13, \\
& 2012, pp. 32-41.
\end{tabular}




\section{The levels-of-approximation approach in MC 2010: application to punching shear provisions}

In order to address how new knowledge influences design expressions, design codes have in most cases become significantly more complex over the last decades. However, this tendency is leading to codes that are too complicated for preliminary design but still not sufficiently accurate for assessing existing structures (where even more realistic models of behaviour are sometimes required). An alternative code strategy is that proposed by codes based on a levels-of-approximation (LoA) approach. This approach is based on the use of theories based on physical parameters where the hypotheses for their application can be refined as the accuracy required increases. The approach proposes adopting safe hypotheses during the first stages of design, leading to relatively quick and simple analyses. In cases where such a degree of accuracy is not sufficient (e.g. design of complex structures, assessment of existing structures, significant potential economic savings), the hypotheses can be refined in a number of steps, leading to better estimates of the behaviour and strength of members. This approach, recently adopted in the first complete draft of Model Code 2010 for a number of design issues, is discussed within this paper with reference to punching shear provisions.

Keywords: levels-of-approximation approach, design codes, Model Code 2010, assessment of structural safety, critical shear crack theory

\section{Introduction}

Most experienced engineers have always tackled the problem of designing new structures or assessing the strength of existing ones by following a levels-of-approximation (LoA) approach. This is rather intuitive as the limits to the strength of a structure can usually be calculated with fairly simple models. Provided that such models are based on sound theories, some of their physical parameters (e.g. angles of compression struts or effectiveness factors) can be better estimated by devoting more time to their analysis, leading to improved (typically higher) estimates of the strength of a member.

However, this design strategy has not always been reflected in codes of practice, where in many instances it is not possible to refine the parameters used in their design expressions. This is typically the case with empirical for-

\footnotetext{
* Corresponding author: miguel.fernandezruiz@epfl.ch
}

Submitted for review: 12 July 2011

Revised: 20 September 2011

Accepted for publication: 20 September 2011 mulas based on geometrical dimensions and material properties, but not on physical parameters. As a consequence, codes seldom overrule most aspects of design (which is usually time-consuming and leaves little opportunity for designers to use advanced state-of-the art design methods) or are excessively open (which might be dangerous in the hands of inexperienced designers). In order to address the influence of new knowledge on design expressions suitably, codes are also increasing in complexity (particularly when empirical models are used). This tendency is leading to codes that are sometimes too complicated for preliminary design but still not sufficiently accurate for assessing existing structures (where even more realistic models of behaviour are sometimes required). In many countries this is giving rise to a debate on the need for "concise codes" for designing simple structures and "assessment codes" for existing structures. However, their design models are not always consistent and this leads to confusion for designers.

An alternative code strategy is that proposed by the LoA approach [1, 2], see Fig. 1. This approach proposes using theories based on physical models. When preliminary estimates of the strength of a member are required, the mechanical parameters of the design expressions can be assessed in a simple (yet safe) manner. This allows the limits of strength to be determined even though very little time needs to be devoted to the analyses, which is normally sufficient for preliminary design purposes and even for many structural members without a given governing failure mode. However, in cases where such a degree of accuracy is not sufficient (e.g. critical elements, detailed design), the values of the mechanical parameters can be refined in a number of steps. This means devoting more time to analyses, see Fig. 1, but leads to better estimates of

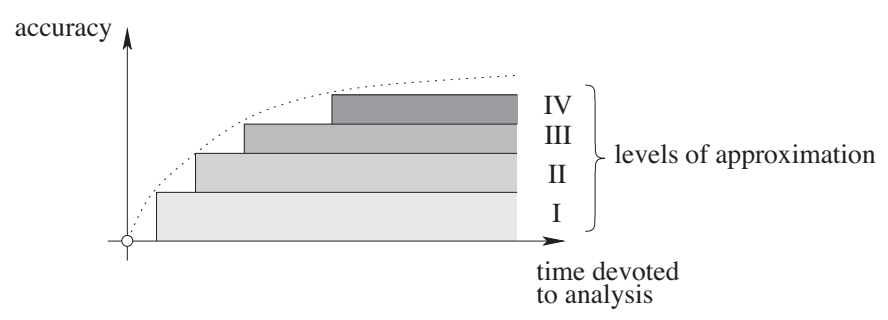

Fig. 1. Levels-of-approximation approach: accuracy of the estimate as a function of the time devoted to analyses (adapted from [1]) 
the behaviour and strength of members. The LoA approach thus allows the preliminary design phases as well as advanced designs and assessments to be covered with the same set of expressions.

With respect to the design of new structures, this approach allows for a gradual increase in the accuracy of the analyses as the project evolves from preliminary design studies to a construction project. This helps to expend the necessary time at each design stage. It also allows a refined design to be carried out for unusual elements with special significance regarding the safety of the structure (e.g. discontinuity regions or coupling members).

And the incremental approach is also very convenient when assessing existing structures which, even if they were correctly designed according to codes of practice at the time they were built, might not comply with current code recommendations due to changes in loads or more stringent code provisions. This does not mean, however, that such structures are unsafe. Design rules are provided to cover a series of uncertainties and to be applied to a wide number of cases, although they might be excessively conservative in some situations. In these cases, the use of more refined analysis methods to assess the structural safety is fully justified (even if they are more timeconsuming) as expensive strengthening can be avoided.

The LoA approach was formally presented [1] and implemented for the calculation of second-order effects in the Swiss Code for structural concrete [3] in 2003. Recently, it has also been considered in the first complete draft of Model Code 2010 [4, 5] for shear, punching shear and buckling design. In this paper, the fundamentals of this approach are presented with reference to the punching shear provisions of Model Code 2010. A practical example of the use of this approach is also introduced, helping the reader to understand the increase in accuracy expected as higher levels of approximation are employed.

\section{The LoA approach for punching shear in Model Code 2010}

Punching shear has been a topic of research in structural concrete since the 1960s. The first rational approach to punching shear design was developed in Sweden by Kinnunen and Nylander [6]. This approach successfully explained the behaviour and strength of punching shear in flat slabs without transverse reinforcement. Although the approach of Kinnunen and Nylander was rather satisfying, it resulted in somewhat complicated design expressions. As a consequence, its implementation in codes of practice was difficult and currently most codes of practice both in Europe [7] and in America [8] are still based on empirical expressions without a physical basis for the punching shear design of members without transverse reinforcement. In order to provide a better understanding of the phenomenon, intensive research has been performed in recent decades. A detailed state of the art report and comparisons of approaches can be found in specialized publications [9, 10] and research works [11, 12].

Following these investigations, and contrary to previous editions of the Model Code, the punching shear provisions in Model Code 2010 are based on a physical theory rather than on empirical formulas. The theory behind MC

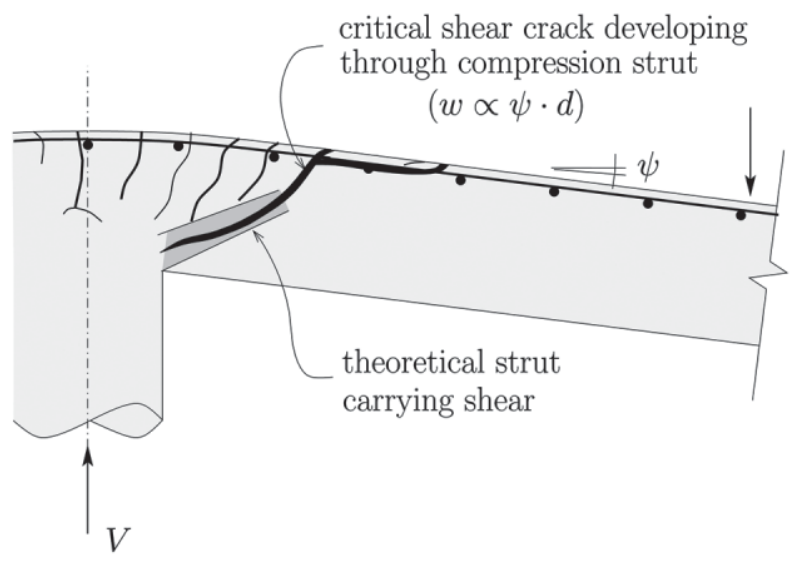

(a)

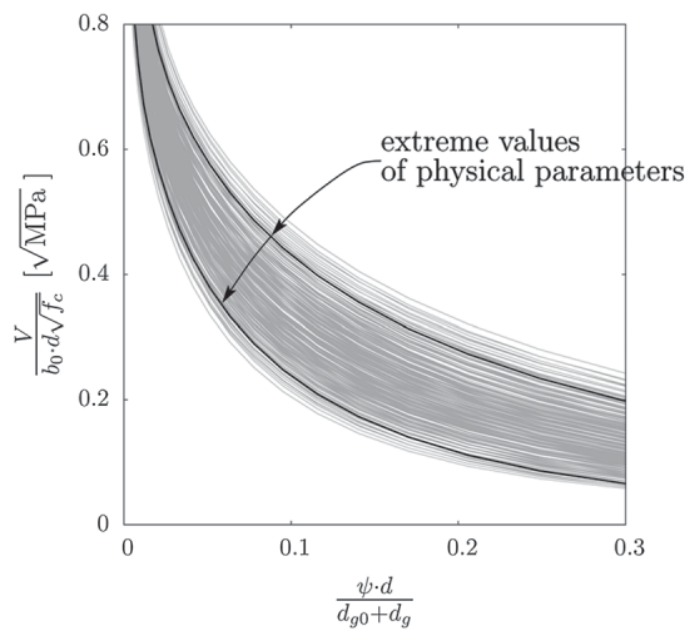

(b)

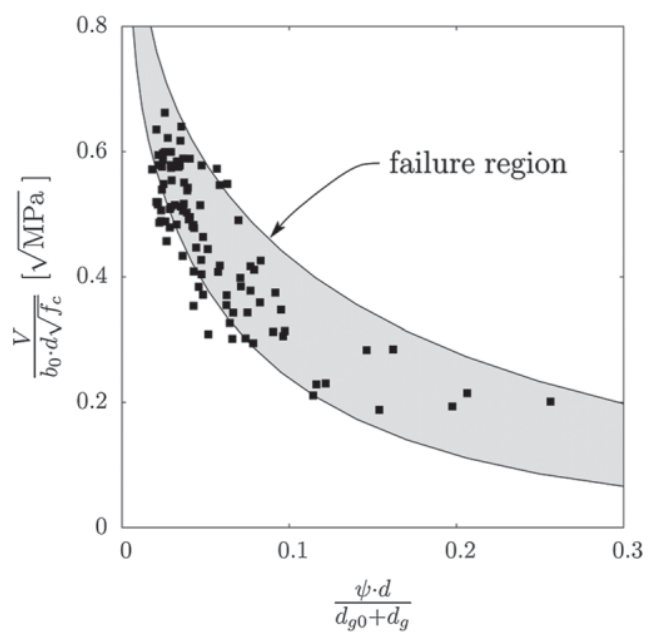

(c)

Fig. 2. Critical shear crack developing through the compression strut: (a) location of strut and critical shear crack [12], (b) failure envelopes for reinforced concrete slabs as a function of slab rotation (results for specimens with effective depth of $95-450 \mathrm{~mm}$, flexural reinforcement ratio of 0.4-1.6\%, concrete strength of 15-60 MPa, aggregate size of 8-32 mm and column diameter of $100-200 \mathrm{~mm}$ ), and (c) comparison of failure band and results from 99 punching shear tests [12]

2010 provisions is critical shear crack theory (CSCT). The basic principles of CSCT with respect to punching shear design were developed by Muttoni and Schwartz in 1991 [13] and were later refined and extended to shear design of one-way members by Muttoni [14]. A series of recent experimental and theoretical works have provided justifica- 
tion for its mechanical model $[12,15,16]$ and have also extended its use to members failing in shear after developing plastic strains in the flexural reinforcement [17, 18], shearreinforced slabs [19, 20] and other topics. An extended summary of recent developments and applications can be found elsewhere [21].

\subsection{Mechanical model of CSCT}

Critical shear crack theory is based on the assumption that the shear strength in members without transverse reinforcement is governed by the width and roughness of a shear crack that develops due to the inclined compression strut carrying shear [12,15], see Fig. 2a. The shear strength resulting from this assumption can be calculated by assuming two rigid bodies with kinematics at failure characterized by the rotation of the slab (developed in agreement with test measurements [16]). Assuming such kinematics, both tensile stresses and stresses due to aggregate interlock (relative slip between the lips of the crack) develop along the critical shear crack. The shear strength can thus be calculated by integrating both contributions (concrete in tension and aggregate interlock) along the failure surface (dowel action is neglected due to spalling of the concrete cover to the flexural reinforcement, Fig. 2a).

Fig. $2 \mathrm{~b}$ shows the results obtained by performing such integration, using the numerical approach detailed in [16] and for significant variations of the mechanical parameters implied. The plot is normalized on both axes to account for support region size, concrete compressive strength, member depth and aggregate size. It can be seen that the punching shear strength decreases as rotation and effective depth increase (leading to greater openings of the critical shear crack). This is logical because wider cracks reduce both the concrete in tension and aggregate interlock contributions. It is also interesting to note that failures occur in a well-defined and rather narrow band for all cases (Fig. 2b). Comparing the failure region with the results of 99 punching shear tests (whose data is detailed elsewhere [12]) is shown in Fig. 2c, showing a very satisfactory agreement.

For design purposes, and taking into account the narrow width of the failure band, detailed calculation of the failure envelopes by integrating concrete in tension and aggregate interlock contributions is not usually necessary. For these cases, a simplified failure criterion was proposed by Muttoni [14, 12]. It assumes that the punching shear strength (traditionally correlated to the square root of the concrete compressive strength after the works of Moody et al. [22]) is a function of the width and roughness of a shear crack as justified by the previous mechanical model:

$\frac{V_{R}}{b_{0} \cdot d_{v}}=\sqrt{f_{c}} \cdot f\left(w, d_{g}\right)$

where:

$V_{R} \quad$ shear strength

$b_{0}$ shear-resisting control perimeter (set at $d_{v} / 2$ of the edge of the support region assuming a uniform distribution of shear forces)

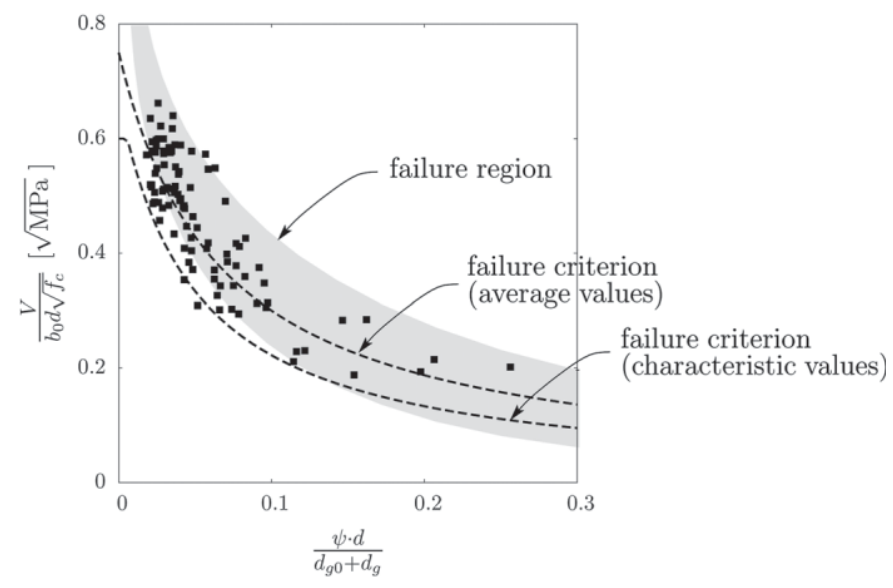

Fig. 3. Comparison of failure region (Fig. 2c) and average and characteristic CSCT failure criteria

$d_{v}$ shear-resisting effective depth of member (distance between centroid of flexural reinforcement and the surface at which the slab is supported)

$f_{c} \quad$ compressive strength of concrete

$w$ width of critical shear crack

$d_{g}$ maximum size of aggregate (accounting for the roughness of the lips of the cracks)

In order to evaluate the width of the critical shear crack $w$, Muttoni and Schwartz [13] assumed it to be proportional to the slab rotation $\psi$ multiplied by the effective depth of the member (see Fig. 2a):

$w \propto \psi \cdot d$

Based on these assumptions, the following failure criterion was proposed by Muttoni $[14,12]$ for members without shear links and assuming average values for the strength:

$\frac{V_{R}}{b_{0} \cdot d_{v} \cdot \sqrt{f_{c}}}=\frac{3 / 4}{1+15 \frac{\psi \cdot d}{d_{g 0}+d_{g}}}$

where:

$d_{g 0}$ reference aggregate size equal to $16 \mathrm{~mm}$

$d \quad$ is to be introduced in [mm].

In Fig. 3 this equation is compared with the failure band calculated on the basis of the mechanical model, showing good agreement. For design purposes, a characteristic failure criterion has to be adopted (target $5 \%$ fractile, refer to Muttoni [12] and Model Code 2010 [5]), see Fig. 3:

$\frac{V_{R d}}{b_{0} \cdot d_{v} \cdot \frac{\sqrt{f_{c k}}}{\gamma_{c}}}=\frac{1}{1.5+0.6 \cdot \psi \cdot d \cdot k_{d g}} \leq 0.6$

where $k_{d g}$ is a coefficient accounting for the maximum aggregate size $d_{g}$, whose value can be calculated as $k_{d g}=48[\mathrm{~mm}] /\left(16+d_{g}\right)$. 


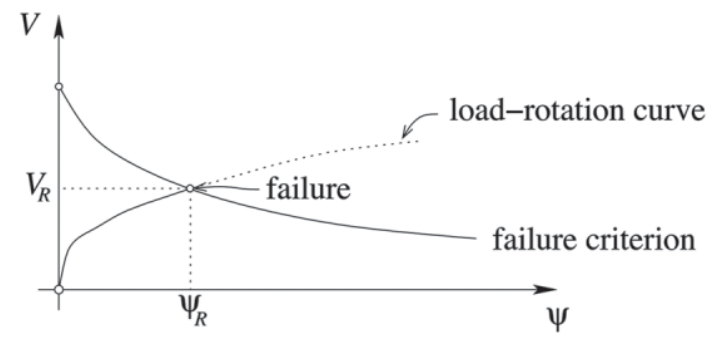

Fig. 4. Calculation of failure point according to CSCT: intersection between failure criterion and load-rotation curve

\subsection{Calculation of failure load}

The punching shear strength of a slab without shear reinforcement can be directly calculated using the CSCT failure criterion. To do so, the intersection between the failure criterion and the actual behaviour of the slab (characterized by its load-rotation curve) has to be calculated, see Fig. 4. It should be noted that this procedure allows not only the calculation of the punching strength but also the estimation of the deformation capacity (rotation) at failure. This provides the designer with valuable information on the behaviour of the structure (e.g. ductility, brittleness). Moreover, the rotation (as an estimate of the shear crack opening) can be used to calculate the activation of the transverse reinforcement for shear-reinforced slabs [19] or to estimate how fibres contribute to punching shear strength [21], accounting for their softening behaviour.

\subsection{Application to shear-reinforced slabs}

The theory can also be consistently applied to shear-reinforced slabs. A number of potential failure modes can develop $[19,20]$ such as: punching within the shear-reinforced area, punching outside the shear-reinforced area, crushing of concrete struts, delamination of concrete core, shear reinforcement pull-out, flexural failures. Details of the way these failure modes can be treated within the frame of CSCT are investigated in depth elsewhere $[19,20$, 21].

Of particular significance is the failure mode by punching within the shear-reinforced zone, see Fig. 5a. The strength in this case depends on the contributions of the concrete and the transverse reinforcement:

$V_{R d}=V_{R d, c}+V_{R d, s}$

This fact has been acknowledged by most design models. However, most codes of practice still propose empirical formulations for estimating the contributions of the two terms. For instance, a constant reduction in the concrete contribution with respect to the strength of members without shear reinforcement is provided for in EC-2 (25\%) [7] and ACI 318-08 [8] (50 \%). These codes also give empirical formulas or constant values for the stress in the shear reinforcement.

The CSCT approach is, however, rather different and takes advantage of the physical hypotheses of the theory. This approach can be understood with the help of Fig. 5a,
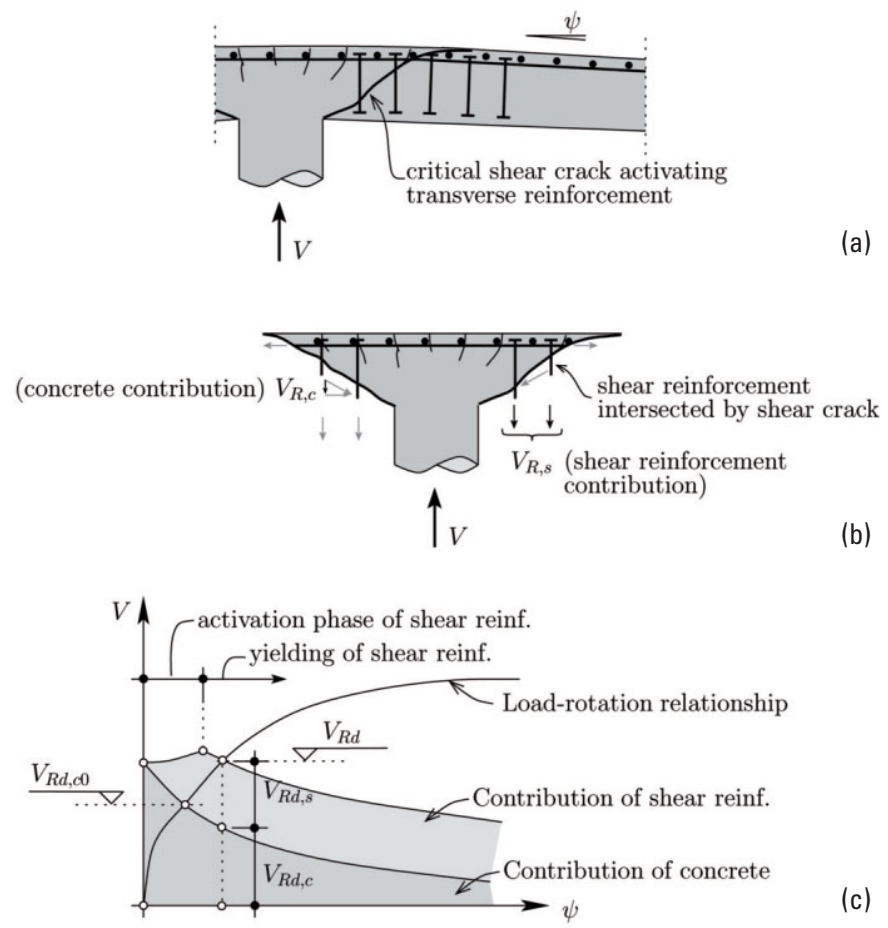

Fig. 5. Slabs with transverse reinforcement: (a) activation of shear reinforcement by critical shear crack, (b) concrete and shear reinforcement contributions, and (c) sum of concrete and shear reinforcement contributions as a function of slab rotation

which shows that the transverse reinforcement is activated as the critical shear crack opens (Fig. 5b). This means that the stresses in the reinforcement increase until they eventually reach their yield strength. On the other hand, the concrete's contribution to the strength decreases with the opening of the shear crack (Fig. 3). This is consistent with the assumptions of empirical codes but allows the calculation of a suitable reduction in the contribution of the concrete $\left(V_{R d, c} / V_{R d, c 0}\right.$ ratio in Fig. 5c) for each specific case on the basis of the rotation (deformation capacity) at failure.

With respect to the activation of the shear reinforcement, suitable analytical laws have been derived elsewhere $[19,20]$ as a function of the slab rotation (correlated to the critical shear crack opening) and bond conditions of the reinforcement. A code-like formulation of these models $[19,26]$, accounting for bond and inclined reinforcement, has recently been introduced in the first complete draft of Model Code [5]. In its general formulation, this equation is as follows:

$\sigma_{s w d}=\frac{E_{s} \psi}{6} \cdot(\sin \alpha+\cos \alpha)\left(\sin \alpha+\frac{f_{b d}}{f_{y w d}} \frac{d}{\phi_{w}}\right) \leq f_{y w d}$

where:

$\alpha \quad$ angle between slab axis and shear reinforcement

$f_{b d} \quad$ value of bond strength (which for design purposes can be adopted as $3 \mathrm{MPa}$ for ribbed bars)

$f_{y w d}$ yield strength of shear reinforcement

$\phi_{w} \quad$ diameter of shear reinforcement 


\subsection{Calculating the load-<rotation behaviour using an LoA approach}

Various methods can be used to estimate the load-rotation behaviour necessary to calculate the punching shear strength (Figs. 4 and 5c). Model Code 2010 proposes both simplified formulas derived on the basis of the analytical formulas [12] and numerical procedures.

With respect to the analytical formulas, the general form of the load-rotation relationship proposed by MC 2010 [5] is:

$\psi=1.5 \cdot \frac{r_{s}}{d} \frac{f_{y d}}{E_{s}} \cdot\left(\frac{m_{s d}}{m_{R d}}\right)^{1.5}$

where:

$r_{s} \quad$ distance from column axis to line of contraflexure of radial bending moments

$f_{y d}$ yield strength of flexural reinforcement

$E_{s} \quad$ modulus of elasticity of flexural steel

$m_{s d}$ average moment per unit length for calculating flexural reinforcement in support strip

$m_{R d}$ average flexural strength per unit length in support strip

The values of the various mechanical parameters in the formula can be assessed with different degrees of accuracy, leading to the levels-of-approximation (LoA) approach.

\subsubsection{LoA I}

For preliminary design purposes, a safe hypothesis can be adopted by assuming $m_{s d}=m_{R d}$. This implies that, at failure, bending reinforcement yields over the entire width of the support strip, thus leading to large crack openings (which decreases the punching shear strength). This therefore leads to a safe estimate of the strength because if punching strength satisfies this condition, the strength of the slab will be governed by its bending capacity. Furthermore, slabs satisfying this condition exhibit a very ductile behaviour, avoiding brittle failure problems. The load-rotation equation is therefore:

$\psi=1.5 \cdot \frac{r_{s}}{d} \frac{f_{y d}}{E_{\mathrm{s}}}$

where for regular flat slabs the value of $r_{s}$ can be calculated on the basis of the span length as $r_{s} \approx 0.22 \ell$ (calculated based on the geometry of the structure).

\subsubsection{LoA II}

Approximation level II is a simplified estimate of the moment acting in the support strip $m_{s d}$. This is carried out with an analytical expression relating the moment in the support strip to the shear force acting $V_{E d}$ and the moment transferred from the slab to the support region (characterized by its eccentricity $e_{u}$ ). For instance, for inner columns of flat slabs: $m_{s d}=V_{E d}\left(\frac{1}{8}+\frac{e_{u}}{2 b_{s}}\right)$

where:

$V_{E d} / 8$ average moment for calculating flexural reinforcement acting in support strip without moment transfer

$V_{E d} \cdot e_{u}$ moment transferred to column

$2 b_{s} \quad$ width where this transferred moment acts (half the moment acting on each side of the column)

In spite of its simplicity, this expression provides excellent estimates of the load-rotation behaviour of a slab as shown elsewhere $[12,21]$. For instance, the ratio between the measured and calculated punching shear strengths for the tests in Fig. $2 \mathrm{c}$ is 1.07, with a coefficient of variation of $9 \%$ (significantly better than most design codes [12]).

\subsubsection{LoA III}

If a linear-elastic analysis is performed for designing the flexural reinforcement in a flat slab, the resulting moment field can be used to improve the estimate of the mechanical parameters of Eq. (7). This is, for instance, simple for the values of $r_{s}$ and $m_{s d}$, where bending and torsion moments can be integrated directly for the latter.

In this case, and due to the better estimate of the various parameters, coefficient 1.5 in Eq. (7) can be replaced by 1.2 (leading to stiffer behaviours and thus to higher strengths for equal mechanical parameters):

$\psi=1.2 \cdot \frac{r_{s}}{d} \frac{f_{y d}}{E_{s}} \cdot\left(\frac{m_{s d}}{m_{R d}}\right)^{1.5}$

\subsubsection{LoA IV}

In some special cases, the load-rotation behaviour of a flat slab can be investigated by integrating the moment-curvature diagrams of the structure directly. This is justified, for instance, if expensive strengthening can be avoided by performing a more refined analysis. However, it should be borne in mind that such analyses are very time-consuming and that the accuracy of LoA III is already very satisfactory. Significant improvements in the strength by using this level should only be expected for slabs with fairly low reinforcement ratios over columns (with significant tensionstiffening effects) or when large redistributions of bending moments between column and mid-span regions are expected.

Procedures for the numerical integration have been presented elsewhere [23, 24, 26]. Many commercial software packages also provide tools for such analyses. These methods are, however, generally sensitive to the choice of the parameters involved and should be applied by experienced users who have previously checked the results of the numerical simulations against actual tests. 


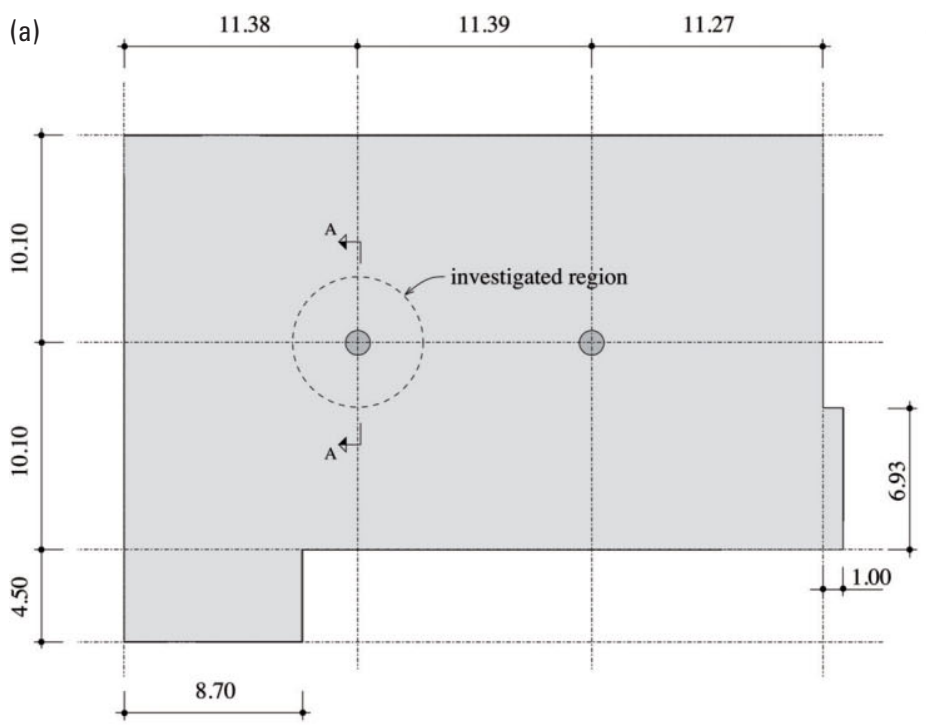

(c)

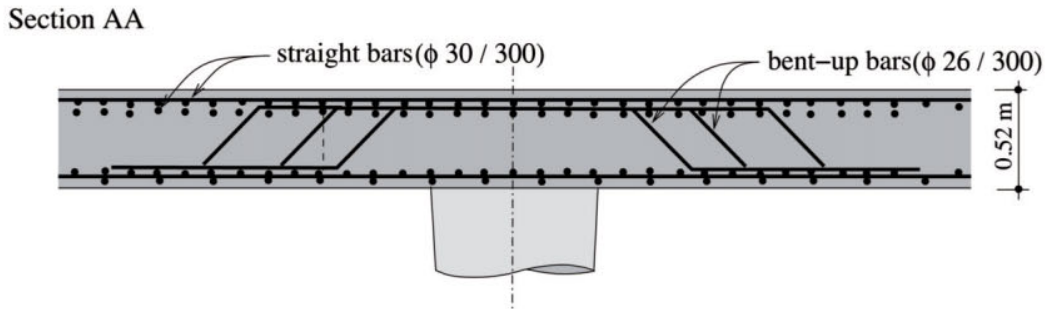

(b)

Fig. 6. Example of application: (a) geometry and region investigated, (b) cross-section over column, and (c) governing load case

\section{Choice of a suitable LoA}

The choice of a suitable level of approximation depends mostly on the context of the analysis performed (preliminary or detailed calculations) and on the potential savings that can be achieved if a more refined level of approximation is performed. In general, this choice is a decision that belongs to the designer, but some objective criteria to guide this choice are provided below.

LoA I provides simple and safe hypotheses for evaluating the physical parameters of design equations. It is quick and simple and thus is in most cases sufficient for preliminary design purposes. Another significant use of LoA I is to check whether a given failure mode cannot govern. This is the case for structures where sufficient strength is provided even under the safe assumptions of LoA I. In such cases, it is unnecessary to perform further analyses using more accurate levels of approximation.

For more accurate levels of approximation, the physical parameters of design equations are evaluated through simplified analytical formulas. These levels are again quick and are usually sufficient to cover most design cases. Their use is advised for tender and detailed design of most new structures as well as for assessing existing structures.

As the most refined level of approximation, numerical methods can be used to estimate the value of the physical parameters considered by the design equations (numerical integration of the moment-curvature diagrams of the structure). The use of such levels is typically very time-consuming and only advised for the de- tailed design of very complex structures or for the assessment of critical existing structures. This is justified when a more accurate estimate can lead to significant savings for the client (avoiding or limiting the strengthening of structures).

\section{Example of application}

This section explains the use of the levels-of-approximation approach with the help of a practical example. It consists on the assessment of the strength of an existing flat slab built in the 1970s in Switzerland. The slab has a constant thickness of $0.52 \mathrm{~m}$ and is supported on a series of walls around its periphery and by two inner columns (with a diameter of $1.20 \mathrm{~m}$ at the slab support point), see Fig. 6a. Concrete compressive strength was updated by tests to a value of $f_{c k}=59.4 \mathrm{MPa}$ (accounting for long-term effects) and the maximum aggregate size is $32 \mathrm{~mm}$. The slab has large amounts of flexural reinforcement in the column region, with average ratios in the support strips of $\rho=1.7 \%$ in the $x$ direction and $\rho=1.4 \%$ in the $y$ direction. The reinforcement yield strength is $f_{y d}=390 \mathrm{MPa}$. The slab also has a number of bent-up bars (16 sections of bars $16 \mathrm{~mm}$ diameter inclined at $45^{\circ}$ and intersected by the conical punching failure surface). It is subjected to self-weight, earth cover and traffic loads. The geometry and governing load case for punching shear strength are shown in Figs. 6a and $6 \mathrm{~b}$. The structure was analysed and eventually strengthened following the guidelines of MC 2010. In this paper, only the evaluation of its punching shear strength will be discussed. 


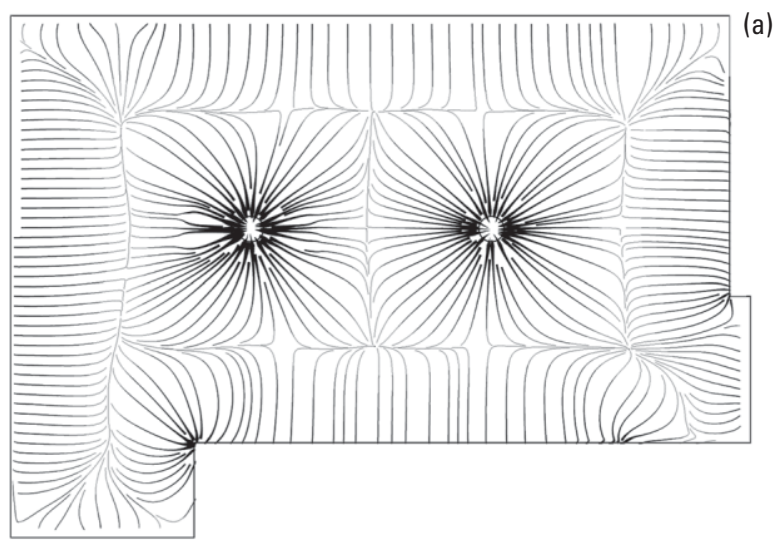

Fig. 7. Shear field analysis: (a) shear field of flat slab for governing load case, and (b) distribution of shear forces along control perimeter

\subsection{LoA I}

A preliminary estimate of the punching shear strength can be obtained using LoA I. The total shear acting on the control perimeter can be obtained from a linear analysis of the structure (column reaction minus forces acting within control perimeter) as $V_{E d}=5.54 \mathrm{MN}$. The minimum strength corresponds in this case to the direction of maximum rotation (maximum span length), which can be calculated from Eq. (8):

$\psi_{\max }=1.5 \frac{r_{s}}{d} \frac{f_{y d}}{E_{s}}=1.5 \frac{0.22 \cdot 11.39}{0.45} \frac{390}{200000}=1.63 \%$

For estimating the strength, the shear-resisting control perimeter $b_{0}$ has to be reduced with respect to the total perimeter available at a distance $d_{v} / 2$ from the border of the support region (designated the basic control perimeter $b_{1}$ in Model Code 2010) to account for concentrations on the shear field. This can be done by applying the following relationship [5]:

$b_{0}=k_{e} \cdot b_{1}$

Approximated values for the coefficient of eccentricity $k_{e}$ are provided in Model Code 2010 [5]. However, as stated in the code, due to the presence of significant concentrated loads in the vicinity of the support region, larger shear concentrations than those considered by the values of Model Code 2010 can occur. Thus, instead of a value $k_{e}=0.90$ (corresponding to inner columns of flat slabs subjected to distributed loads according to Model Code 2010) a safer value $k_{e}=0.80$ will be adopted [25]. This choice will be discussed and refined below.

The concrete and reinforcement contributions can thus be directly calculated for the governing rotation:

$$
\begin{aligned}
V_{R d}=V_{R d, c} & +V_{R d, s}=\frac{b_{0} \cdot d_{v} \cdot \sqrt{f_{c k}} / \gamma_{c}}{1.5+0.6 \psi_{\max } d \cdot k_{d g}}- \\
& +A_{s w} \cdot k_{e} \cdot \sigma_{s w d} \cdot \sin \alpha=1.63+1.87=3.50
\end{aligned}
$$

where the shear reinforcement contribution can be calculated on the basis of Eq. (6), leading to $\sigma_{s w d}=390 \mathrm{MPa}$ (yield strength). In this case, other potential failure modes (crushing of concrete struts, punching at other perimeters) are not governing.

The compliance factor $\left(n=V_{R d} / V_{E d}\right)$ is then 0.63 , which can be considered as very low, advising urgent measurements.

\subsection{LoA II}

A better estimate of the punching shear strength can be obtained by using the results of a linear-elastic analysis. Coefficient $k_{e}$ can be estimated on the basis of the shear field of the structure around the column region, see Fig. 7. This figure shows concentrations of the shear field near the concentrated loads to the left of the column (where heavier concentrated loads are applied). In such a case, according to Model Code 2010, the coefficient of eccentricity can be calculated as:

$k_{e}=\frac{V_{d}}{v_{\text {perp }, d, \max }} \cdot \frac{1}{b_{1}}=0.78$

where $v_{\text {perp, } d \text {, max }}$ corresponds to the maximum value of the shear force component per unit length perpendicular to the basic control perimeter, see Fig. $7 \mathrm{~b}$. This value shows that the previous estimate (level I) for the coefficient of eccentricity was already rather good. In LoA II, the load-rotation curves are calculated based on Eq. (7) and estimating $m_{s d}$ according to the expressions is provided by level II of MC 2010, $m_{s d}=V_{E d}\left(1 / 8+e_{u} /\left(2 b_{s}\right)\right)$. The parameters required, $r_{s x}\left(=0.22 \ell_{x}=2.51\right)$ and $r_{s y}$ $\left(=0.22 \ell_{y}=2.22\right)$, can be obtained by considering the geometry.

The results are plotted in Fig. 8a. In this figure, the concrete strength $\left(V_{R d, c}\right.$, estimated according to Eq. (4)), the contribution of the shear links $\left(V_{R d, s}\right.$, estimated according to Eq. (6)) and the load-rotation behaviour of the slab (estimated according to Eqs. (7) and (9)) are plotted as a function of the rotations in the $x$ and $y$ directions (maximum punching shear strength is not governing). The result yields $V_{R d}=4.22 \mathrm{MN}$, with the $y$ direction governing. The compliance factor $\left(n=V_{R d} / V_{E d}\right)$ is 0.76 , still rather low but not so critical as in LoA I.

It can be seen that in this case the stress in the transverse reinforcement is $\sigma_{s w d}=271 \mathrm{MPa}$, which is below the yield strength (contrary to the outcome of LoA I). This is 

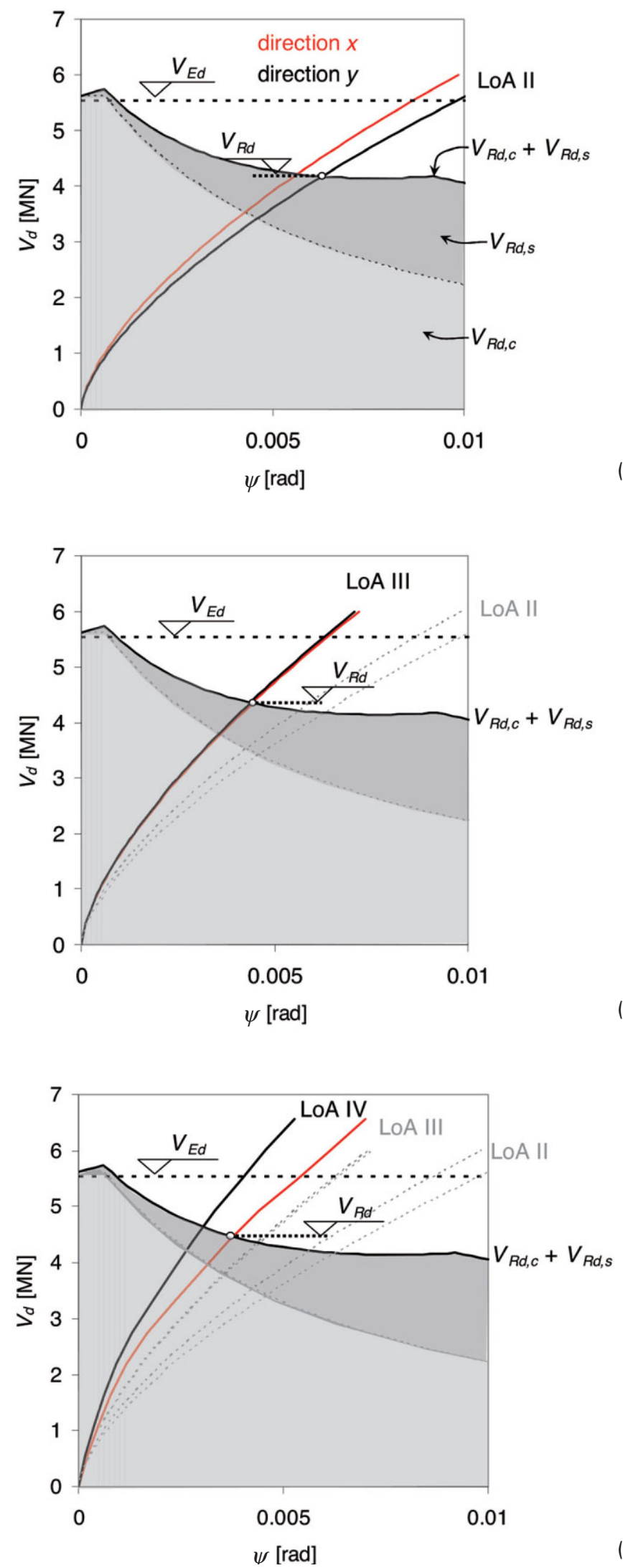

Fig. 8. Results for the various levels of approximation: (a) LoA II, (b) LoA III, and (c) LoA IV

due to the fact that the rotation at failure $(\psi=0.64 \%)$ is smaller than that estimated in LoA I. However, although the contribution of the shear reinforcement decreases, the total strength increases because the concrete contribution is larger for smaller rotations. From the plot of Fig. 8a, it can also be seen that the structure will most probably not have sufficient strength $\left(V_{R d}<V_{E d}\right)$ even if more refined levels of approximation are used (the strength of the slab is only higher than the action for very limited rotations). However, the analysis with higher levels of approximation can still be interesting for the optimization of the potential strengthening [20]. This was the case in this example, which justified more in-depth analyses by using higher LoAs.

\subsection{LoA III}

Taking advantage of the linear analysis performed, values of $m_{s d}$ and $r_{s}$ can be estimated in a more accurate manner from the moment field as described in MC 2010. The values of $r_{s}$ are 2.48 and $2.61 \mathrm{~m}$ for the $x$ and $y$ directions respectively (fairly in agreement with the estimates of LoA II). Integrating the bending moments leads to the result shown in Fig. 8b. The results provide a slightly higher strength prediction, although with a limited gain. The punching shear strength is $V_{R d}=4.35 \mathrm{MN}$, leading to a compliance factor of $n=0.78$.

\section{$4.4 \quad$ LoA IV}

Finally, a refined analysis of the load-rotation behaviour was performed using a non-linear finite element model. The model was local (slab between mid-span axes) and consisted of 32 regions where the different reinforcement near the column region, the support strips and the field where considered. The results are shown in Fig. $8 \mathrm{c}$, where it can be seen that the result is only a limited increase in the strength, with a value of $V_{R d}=4.46 \mathrm{MN}$ leading to a compliance factor of $n=0.80$. This result is consistent with other works [12], showing that the MC 2010 expressions for LoA II and III are quite accurate for the flexural behaviour of slabs with large amounts of bending reinforcement and safer for slabs with low amounts of flexural reinforcement (where tension-stiffening effects can play a significant role).

\subsection{Comments on the results}

The results obtained confirm that the estimate of the accuracy of the punching shear strength can be refined progressively by using the levels-of-approximation approach. This is possible because a better estimate of the physical parameters of the design model is provided in each subsequent level of approximation (LoA). LoA I and II can be performed in just a couple of minutes. LoA III required more than twice that time. LoA IV, as performed in this example, took some days. The gain in the estimated strength is, however, limited, and LoA II or III are usually sufficient for detailed designs and assessments. In this case (due to the complexity of the location of the flat slab) all levels were performed in order to optimize the amount of shear reinforcement and the method to be used during retrofitting.

\section{Conclusions}

This paper has discussed the main ideas of the levels-of-approximation (LoA) approach for designing and assessing 
structures. Its use in the new Model Code 2010 is also explained with reference to the punching shear chapter and an example of an application to a real structure is presented. The main conclusions of the paper are:

1. The LoA approach is based on the idea that consistent (physically sound) theories should be used for design. The various mechanical parameters used within these theories can be estimated using different degrees of accuracy.

2. When little work is devoted to the analysis (first levels of approximation), safe (yet realistic) values of the strength and behaviour of structural members should be provided by this approach.

3. The accuracy can be increased thereafter by performing additional analyses. This allows a better estimation of the physical parameters required by the design equations.

4. Such an approach is convenient for designing or assessing structures:

a. With respect to design, it allows an increase in the accuracy of the analyses as the project evolves from a conceptual design to a construction project.

b. With respect to the assessment of existing structures, it allows the refinement of some hypotheses adopted for design (typically safe and introduced to cover a broad range of cases). In these cases, devoting a significant amount of time to the analyses is certainly justified if expensive (and unnecessary) strengthening can be avoided.

5. The first complete draft of Model Code 2010 proposes following the LoA approach with respect to shear, punching shear and buckling. Consistent design models have been obtained, encouraging the extension of the LoA approach to other domains.

\section{Acknowledgements}

The authors have implemented the ideas of the LoA approach into Model Code 2010 within the scope of fib Task Group 4.2. The authors would like to thank the other members of the editorial group of TG 4.2 (Evan Bentz, Stephen Foster and Viktor Sigrist) as well as Joost Walraven.

The authors are also appreciative of the comments and suggestions of Karel Thoma and Bruno Zimmerli (i-beratung $\mathrm{GmbH}$, Switzerland) for the example presented within this paper.

\section{Notation}

$\begin{array}{ll}A_{s w} & \text { cross-sectional area of shear reinforcement } \\ E_{S} & \text { modulus of elasticity of reinforcement } \\ V & \text { shear force } \\ V_{E d} & \text { design value of shear force acting } \\ V_{R} & \text { punching shear strength } \\ V_{R d} & \text { design punching shear strength } \\ V_{R d, c} & \text { design concrete contribution to punching shear } \\ & \text { strength } \\ V_{R d, \text { max }} & \text { maximum punching shear strength } \\ V_{R d, s} & \text { design shear reinforcement contribution to } \\ & \text { punching shear strength } \\ b_{0} & \text { shear-resisting control perimeter }\end{array}$

\begin{tabular}{|c|c|}
\hline$b_{1}$ & basic control perimeter \\
\hline$b_{s}$ & strip width \\
\hline$d_{v}$ & shear-resisting effective depth \\
\hline$d$ & effective depth \\
\hline$d_{g}$ & maximum diameter of aggregate \\
\hline$d_{g 0}$ & reference aggregate size $(16 \mathrm{~mm})$ \\
\hline$e_{u}$ & $\begin{array}{l}\text { load eccentricity with respect to centroid of ba- } \\
\text { sic control perimeter }\end{array}$ \\
\hline$f_{b d}$ & design bond strength \\
\hline$f_{c}$ & $\begin{array}{l}\text { average compressive strength of concrete } \\
\text { (cylinder) }\end{array}$ \\
\hline$f_{c k}$ & $\begin{array}{l}\text { characteristic compressive strength of concrete } \\
\text { (cylinder) }\end{array}$ \\
\hline$f_{y d}$ & design yield strength of flexural reinforcement \\
\hline$f_{y w d}$ & design yield strength of shear reinforcement \\
\hline$k_{d g}$ & coefficient for aggregate size \\
\hline$k_{e}$ & coefficient of eccentricity \\
\hline$\ell$ & span length \\
\hline$m_{s d}$ & $\begin{array}{l}\text { average moment per unit length (design of flex- } \\
\text { ural reinforcement) in strip }\end{array}$ \\
\hline$m_{R d}$ & $\begin{array}{l}\text { average flexural strength per unit length in sup- } \\
\text { port strip }\end{array}$ \\
\hline$n$ & compliance factor $\left(=V_{R d} / V_{E d}\right)$ \\
\hline$r_{s}$ & $\begin{array}{l}\text { distance between column and line of con- } \\
\text { traflexure of moments }\end{array}$ \\
\hline$v_{\text {perp,d,max }}$ & $\begin{array}{l}\text { maximum shear force perpendicular to basic } \\
\text { control perimeter }\end{array}$ \\
\hline$w$ & critical shear crack opening \\
\hline$\alpha$ & $\begin{array}{l}\text { angle between slab axis and shear reinforce- } \\
\text { ment }\end{array}$ \\
\hline$\gamma_{c}$ & partial safety factor for concrete \\
\hline$\phi_{w}$ & diameter of shear reinforcement \\
\hline$\rho$ & flexural reinforcement ratio \\
\hline$\sigma_{s w d}$ & design stress in shear reinforcement \\
\hline$\psi$ & rotation of slab outside column region \\
\hline$\psi_{\max }$ & $\begin{array}{l}\text { maximum rotation of slab outside column re- } \\
\text { gion }\end{array}$ \\
\hline
\end{tabular}

\section{Reference}

1. Muttoni, A.: Introduction to SIA 262 code (in French: Introduction à la norme SIA 262), Documentation SIA, D 0182, Zürich, Switzerland, 2003, pp. 5-9.

2. Muttoni, A., Fernández Ruiz, M.: Design through an incremental approach: the Swiss experience, 2010 Joint IABSE-fib Conference, Dubrovnik, Croatia, 2010, p. 8.

3. SIA. Code 262 for Concrete Structures, Swiss Society of Engineers and Architects, Zürich, Switzerland, 2003, p. 94.

4. Fédération Internationale du Béton (fib), Model Code 2010 First complete draft, fédération internationale du béton, Bulletin 55, Lausanne, Switzerland, 2010, vol. 1, p. 318.

5. Fédération Internationale du Béton (fib), Model Code 2010 First complete draft, fédération internationale du béton, Bulletin 56, Lausanne, Switzerland, 2010, vol. 2, p. 312.

6. Kinnunen, S., Nylander, H.: Punching of Concrete Slabs Without Shear Reinforcement, Transactions of the Royal Institute of Technology, No. 158, Stockholm, Sweden, 1960, p. 112.

7. Eurocode 2, Design of concrete structures - Part 1-1: General rules and rules for buildings, CEN, EN 1992-1-1, Brussels, Belgium, 2004, p. 225.

8. ACI, Building Code Requirements for Structural Concrete (ACI 318-08) and Commentary (ACI 318R-08), American Concrete Institute, Farmington Hills, Mich., USA, 2008, p. 473. 
9. fib TG 4.3, Punching of structural concrete slabs, Bulletin 12, fédération internationale du béton, Lausanne, Switzerland, 2001, p. 307.

10. Polak, M. A.: Punching Shear in Reinforced Concrete Slabs, American Concrete Institute, Special Publication SP-232, Farmington Hills, Mich., 2005, p. 301.

11. Hegger, J., Häusler, F., Ricker, M.: Critical review of the punching shear provisions according to Eurocode 2 (in German: Zur Durchstanzbemessung von Flachdecken nach Eurocode 2), Beton- und Stahlbetonbau, vol. 103, No. 2, 2008, pp. 93-102.

12. Muttoni, A.: Punching shear strength of reinforced concrete slabs without transverse reinforcement, ACI Structural Journal, vol. 105, No. 4, 2008, pp. 440-450.

13. Muttoni, A., Schwartz, J.: Behaviour of Beams and Punching in Slabs without Shear Reinforcement, IABSE Colloquium Stuttgart, vol. 62, IABSE, Zurich, Switzerland, 1991, pp. 703-708.

14. Muttoni, A.: Shear and punching strength of slabs without shear reinforcement, (in German, "Schubfestigkeit und Durchstanzen von Platten ohne Querkraftbewehrung"), Beton- und Stahlbetonbau, vol. 98, 2003, pp. 74-84.

15. Muttoni A., Fernández Ruiz, M.: Shear strength of members without transverse reinforcement as function of critical shear crack width, ACI Structural Journal, vol. 105, No. 2, 2008, pp. 163-172.

16. Guidotti, R.: Punching of flat slabs subjected to very large column loading (in French: Poinçonnement des planchersdalles avec colonnes superposées fortement sollicitées), $\mathrm{PhD}$ thesis, École Polytechnique Fédérale de Lausanne, Switzerland, 2010, p. 187.

17. Guandalini, S., Burdet, O., Muttoni, A.: Punching tests of slabs with low reinforcement ratios, ACI Structural Journal, vol. 106, No. 1, 2009, pp. 87-95

18. Vaz Rodrigues, R., Muttoni, A., Fernández Ruiz, M.: Influence of shear on the rotation capacity of R/C plastic hinges, American Concrete Institute, Structural Journal, vol. 107, No. 5, 2010, pp. 516-525.

19. Fernández Ruiz, M., Muttoni, A.: Applications of the critical shear crack theory to punching of R/C slabs with transverse reinforcement, ACI Structural Journal, vol. 106, No. 4, 2009, pp. 485-494.

20. Fernández Ruiz, M., Muttoni, A., Kunz, J.: Strengthening of flat slabs against punching shear using post-installed shear reinforcement, ACI Structural Journal, vol. 107, No. 4, 2010, pp. 434-442.

21. Muttoni, A., Fernández Ruiz, M.: MC2010: The Critical Shear Crack Theory as a mechanical model for punching shear design and its application to code provisions, fédération internationale du béton, Bulletin No. 57, 2010, pp. 31-60.

22. Moody, K. G., Viest, M., Elstner, R. C., Hognestad, E.: Shear Strength of Reinforced Concrete Beams - Part 1: Tests of
Simple Beams, ACI Journal, Proceedings vol. 51, No. 4, 1954, pp. 317-332.

23. Muttoni, A. (ed.), Fernández Ruiz, M., Fürst, A., Guandalini, S., Hunkeler, F., Moser, K., Seiler, H.: Structural safety of parking garages (in French: Sécurité structurale des parkings couverts), Doc. D 0226 SIA, Société Suisse des ingénieurs et des architectes, Zurich, Switzerland, 2008, p. 105.

24. Vaz Rodrigues, R.: Shear Strength of Reinforced Concrete Bridge Deck Slabs, Thèse EPFL, No. 3739, Lausanne, Switzerland, 2007, p. 289.

25. Muttoni, A., Fernández Ruiz, M., Guandalini, S.: Punching of slab bridges (in French: Poinçonnement des ponts-dalles), 4. FBH / ASTRA - study conference „Neues aus der Brückenforschung“, Doc. D0223 SIA, Societé suisse des ingénieurs et architects, Zurich, Switzerland, 2007, pp. 85-94.

26. Tassinari, L.: Asymmetric punching of R/C slabs with shear reinforcement (in French : Poinçonnement asymétrique des dalles en béton armé avec armature de poinçonnement), Thèse EPFL No. 5030, Lausanne, Switzerland, 2011, p. 197.

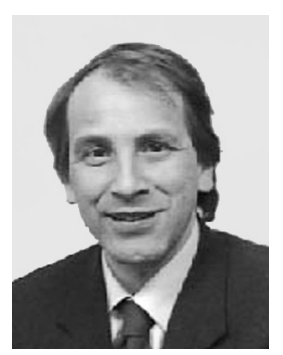

Prof. Dr. Aurelio Muttoni

Ecole Polytechnique Fédérale de Lausanne - ENAC

Station 18

Lausanne $\mathrm{CH}-1024$

Switzerland

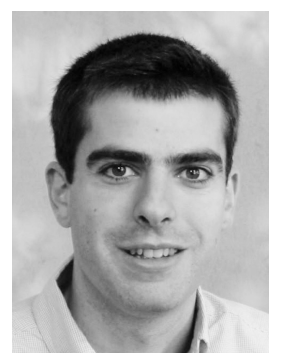

Dr. Miguel Fernández Ruiz

Ecole Polytechnique Fédérale de Lausanne - ENAC

Station 18 Lausanne

CH-1024

Switzerland 